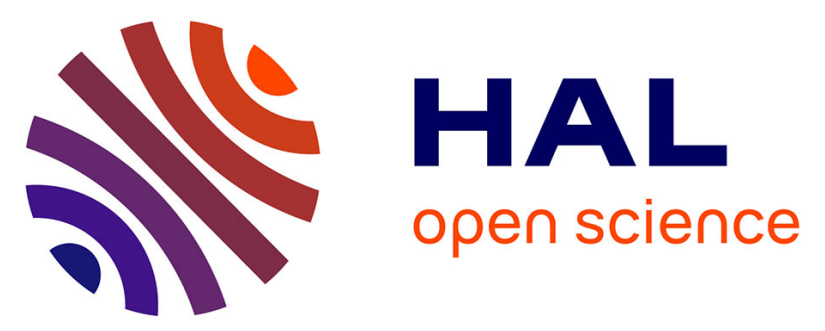

\title{
COPD is deleterious for pericytes: implications during training-induced angiogenesis in skeletal muscle
}

Léo Blervaque, Pascal Pomiès, Elisa Rossi, Matthias Catteau, Adeline Blandinières, Emilie Passerieux, Marine Blaquière, Bronia Ayoub, Nicolas

Molinari, Jacques Mercier, et al.

\section{To cite this version:}

Léo Blervaque, Pascal Pomiès, Elisa Rossi, Matthias Catteau, Adeline Blandinières, et al.. COPD is deleterious for pericytes: implications during training-induced angiogenesis in skeletal muscle. AJP - Heart and Circulatory Physiology, 2020, 319 (5), pp.H1142-H1151. 10.1152/ajpheart.00306.2020 . hal-02956428

\section{HAL Id: hal-02956428 \\ https://hal.science/hal-02956428}

Submitted on 28 Jul 2021

HAL is a multi-disciplinary open access archive for the deposit and dissemination of scientific research documents, whether they are published or not. The documents may come from teaching and research institutions in France or abroad, or from public or private research centers.
L'archive ouverte pluridisciplinaire $\mathbf{H A L}$, est destinée au dépôt et à la diffusion de documents scientifiques de niveau recherche, publiés ou non, émanant des établissements d'enseignement et de recherche français ou étrangers, des laboratoires publics ou privés. 


\title{
COPD is deleterious for pericytes: implications during training-induced
}

\section{angiogenesis in skeletal muscle}

\author{
Léo Blervaque, ${ }^{1}$ Pascal Pomiès, ${ }^{1}$ Elisa Rossi, ${ }^{2}$ Matthias Catteau, ${ }^{1}$ Adeline Blandinières, ${ }^{3}$ \\ Emilie Passerieux, ${ }^{1}$ Marine Blaquière, ${ }^{7}$ Bronia Ayoub, ${ }^{4}$ Nicolas Molinari, ${ }^{5}$ Jacques Mercier, ${ }^{4}$ \\ Antonia Perez-Martin, ${ }^{6}$ Nicola Marchi, ${ }^{7}$ David M. Smadja, ${ }^{3}$ Maurice Hayot, ${ }^{4}$ and Fares Gouzi $^{4}$ \\ ${ }^{1}$ PhyMedExp, INSERM-CNRS-Montpellier University, Montpellier, France; ${ }^{2}$ Université de Paris, Innovative Therapies in \\ Haemostasis, INSERM, Paris, France; ${ }^{3}$ Service d' Hématologie et Laboratoire de Recherches Biochirugicales (Fondation \\ Carpentier), AH-HP, Georges Pompidou European Hospital, Paris, France; ${ }^{4}$ PhyMedExp, INSERM-CNRS-Montpellier \\ University, CHU Montpellier, Montpellier, France, ${ }^{5} I M A G$, CNRS, Montpellier University, CHU Montpellier, Montpellier, \\ France; ${ }^{6}$ Vascular Medicine Department and Laboratory, CHU Nimes and EA2992 Research Unit, Montpellier University, \\ Nimes, France; and ${ }^{7}$ Cerebrovascular and Glia Research, Department of Neuroscience, Institute of Functional Genomics (UMR \\ 5203 CNRS-U1191 INSERM, University of Montpellier), Montpellier, France
}

\begin{abstract}
Blervaque L, Pomiès P, Rossi E, Catteau M, Blandinières A, Passerieux E, Blaquière M, Ayoub B, Molinari N, Mercier J, Perez-Martin A, Marchi N, Smadja DM, Hayot M, Gouzi F. COPD is deleterious for pericytes: implications during training-induced angiogenesis in skeletal muscle. Am J Physiol Heart Circ Physiol 319: H1142-H1151, 2020. First published September 28, 2020; doi:10.1152/ ajpheart.00306.2020.--Improvements in skeletal muscle endurance and oxygen uptake are blunted in patients with chronic obstructive pulmonary disease (COPD), possibly because of a limitation in the muscle capillary oxygen supply. Pericytes are critical for capillary blood flow adaptation during angiogenesis but may be impaired by COPD systemic effects, which are mediated by circulating factors. This study compared the pericyte coverage of muscle capillaries in response to 10 wk of exercise training in patients with COPD and sedentary healthy subjects (SHS). Fourteen patients with COPD were compared with seven matched SHS. SHS trained at moderate intensity corresponding to an individualized moderate-intensity patient with COPD trained at the same relative $\left(\% \dot{\mathrm{V}}_{2}\right.$ : COPD-RI) or absolute $\left(\mathrm{mL} \cdot \mathrm{min}^{-1} \cdot \mathrm{kg}^{-1}\right.$ : COPD-AI) intensity as SHS. Capillary-to-fiber ratio $(\mathrm{C} / \mathrm{F})$ and $\mathrm{NG}_{2}{ }^{+}$ pericyte coverage were assessed from vastus lateralis muscle biopsies, before and after 5 and $10 \mathrm{wk}$ of training. We also tested in vitro the effect of COPD and SHS serum on pericyte morphology and mesenchymal stem cell (MSC) differentiation into pericytes. SHS showed greater improvement in aerobic capacity $\left(\dot{\mathrm{V}}_{2 \mathrm{VT}}\right)$ than both patients with COPD-RI and patients with COPD-AI (Group $\times$ Time: $P=$ $0.004)$. Despite a preserved increase in the $\mathrm{C} / \mathrm{F}$ ratio, $\mathrm{NG}^{+}$pericyte coverage did not increase in patients with COPD in response to training, contrary to SHS (Group $\times$ Time: $P=0.011$ ). Conversely to SHS serum, COPD serum altered pericyte morphology $(P<0.001)$ and drastically reduced MSC differentiation into pericytes $(P<0.001)$. Both functional capacities and pericyte coverage responses to exercise training are blunted in patients with COPD. We also provide direct evidence of the deleterious effect of COPD circulating factors on pericyte morphology and differentiation.
\end{abstract}

NEW \& NOTEWORTHY This work confirms the previously reported impairment in the functional response to exercise training of patients with COPD compared with SHS. Moreover, it shows for the first time that pericyte coverage of the skeletal capillaries is drastically reduced in patients with COPD compared with SHS during training-induced angiogenesis. Finally, it provides experimental

Correspondence: L. Blervaque (leo.blervaque@gmail.com). evidence that circulating factors are involved in the impaired pericyte coverage of patients with COPD.

angiogenesis; COPD; exercise training; pericyte

\section{INTRODUCTION}

Chronic obstructive pulmonary disease (COPD) is a respiratory disease with associated muscle and vascular comorbidities. Aerobic exercise capacity as assessed by maximal oxygen uptake during exercise $\left(\dot{\mathrm{V}}_{\mathrm{O}_{2 \max }}\right)$ is impaired in patients with COPD (45), and the reduced $\dot{\mathrm{V}}_{2 \text { max }}$ is the result of impairments in both muscle convective and diffusive $\mathrm{O}_{2}$ transports (7). The altered diffusive component is due to muscle capillary rarefaction $(55,58,70)$. Improving $\dot{\mathrm{V}}_{\mathrm{O}_{\text {max }}}$ is critical in COPD because it is a determinant of patient quality of life and survival (45). However, we showed that patients with COPD improve less than sedentary healthy subjects (SHS) in both muscle endurance and $\dot{\mathrm{V}}_{\mathrm{O}_{\max }}$ in response to exercise training and that these smaller improvements are related to a defect in muscle capillary creation (26).

Interestingly, recent studies have also pointed to the role of capillaries in the regulation of the convective $\mathrm{O}_{2}$ supply (62), which relies on the vasoactive property of the cells that cover the capillaries: the pericytes (28). Indeed, studies have demonstrated that the control of muscle blood flow at the capillary level depends on pericytes $(29,46,63)$. Specifically, the deletion of pericyte coverage or contraction/relaxation abilities was found to suppress blood flow regulation by capillaries in skeletal muscle $(29,46,63)$. Consistently, greater improvement in capillary blood flow was observed under proangiogenic intervention when capillary pericyte coverage increased, independently of capillary creation $(9,13,14,42,57)$. Lastly, 8 wk of exercise training increased both capillary creation and pericyte coverage of skeletal muscle capillaries (4). Thus, the adaptation of pericyte coverage appears to be an important mechanism in the physiological muscle improvements due to exercise training.

In patients with COPD, we and others have observed that muscle endurance, $\dot{\mathrm{V}}_{2}$ max , and capillary creation show 
impaired responses to training $(26,33)$. We also found ultrastructural impairments in the pericyte/endothelium interactions during training-induced angiogenesis in these patients (5). However, this last study focused on the ultrastructural description of capillaries during training-induced angiogenesis and analyzed only a few numbers of capillaries per subject. Conversely, showing a defective pericyte coverage during capillary maturation requires an assessment of a representative number of capillaries with immunohistochemical analysis (9) and during a longer and more detailed time frame. Pericyte dysfunction was also indirectly observed outside of muscle in these patients-in endoneurial (67) and cerebral capillaries (40) - and pericyte impairment may therefore result principally from a systemic effect of the pathology. The serum of patients with COPD contains numerous deleterious factors (53) and impairs musclederived cells in vitro (12). It thus might mediate this systemic effect. However, direct experimental demonstration of a deleterious effect of COPD circulating factors on pericytes is still lacking.

Therefore, the aims of this study were the following: 1) to compare in vivo the capillary pericyte coverage and capillary creation in response to exercise training in the skeletal muscle of patients with COPD and SHS and to assess their muscle endurance and $\dot{\mathrm{V}}_{\mathrm{O}_{2 m a x}}$, and 2) to provide in vitro experimental evidence of a deleterious effect of COPD circulating factors on pericyte morphology and mesenchymal stem cell (MSC) differentiation into pericytes. To control the effect of exercise intensity or duration on the blunted functional and angiogenic responses, two groups of patients with COPD were trained at either the same relative (\% $\dot{\mathrm{V}}_{2 \text { max }}$ : RI group) or the same absolute $\left(\mathrm{mL} \cdot \mathrm{min}^{-1} \cdot \mathrm{kg}^{-1}\right.$ : AI group) intensity as SHS, in a randomized, controlled double-blind design, and all were evaluated before and after 5 and $10 \mathrm{wk}$ of exercise training.

\section{MATERIAL AND METHODS}

Population. Between December 2013 and May 2015, 14 patients with COPD and seven SHS between 40 and $78 \mathrm{yr}$ old were included and provided informed consent to participate in the study (Ethics Committee No. 2013-A01199-36). The protocol was in line with the Declaration of Helsinki and the European guidelines for good clinical practice and was preregistered in www.clinicaltrials.gov (ClinicalTrials.gov Identifier: NCT02040363). Inclusion criteria for patients with COPD were as follows (69): association of dyspnea, chronic cough, or sputum and/or chronic history of exposure to disease risk factors, a postbronchodilation forced expiratory volume in $1 \mathrm{~s}\left(\mathrm{FEV}_{1}\right)$ /forced vital capacity $(\mathrm{FVC})$ ratio $<0.7$, and no exacerbation episodes in the previous $4 \mathrm{wk}$. The patients also had to present an indication for pulmonary rehabilitation as defined in the official statement as those patients who present "persistent symptoms, limited activity, and/or are unable to adjust to illness despite otherwise optimal medical management" (64). Each control subject was matched for age $( \pm 3 \mathrm{yr})$ and sex with two patients with COPD. They had to be pathology free after medical examination, had to be free from tobacco smoking for $>10 \mathrm{yr}$ with $<10$ pack-years, and had to practice $<150 \mathrm{~min} / \mathrm{wk}$ of moderate-to-vigorous physical activity (Voorrips questionnaire score, $<9.4)$.

Pulmonary rehabilitation. After the cardiopulmonary exercise test (CPET), functional tests, and vastus lateralis biopsies, two exercise training intensities (AI and RI) were determined for each pair of patients with COPD according to the first ventilatory threshold intensity of the matched SHS. The patients were then randomized into the AI or the RI group. Randomization was centralized in the Department of Statistics of Montpellier University Hospital. Investigators, rehabilitation caregivers, the statistician, and patients with COPD were blinded to the training intensity. Then, patients with COPD and SHS participated in $10 \mathrm{wk}$ (36 sessions) of exercise training, which combined endurance and resistance exercises according to international standards and as previously described (26). Sessions of therapeutic education completed the program. Additional details on the exercise protocol can be found in the Supplemental Material (all Supplemental material is available at https://doi.org/10.6084/m9.figshare.12826337).

Functional evaluation and muscle biopsies. Resting lung function was assessed using a plethysmographic spirometer (Medisoft BodyBox 5500 , Belgium). Body composition indices were determined using a segmental multifrequency bioelectronic impedance meter. CPET was conducted using a cyclo-ergometer (Ergometrics 900, Ergo-line, Germany) following international standards (3). Two investigators blindly determined the first ventilatory threshold in SHS following recommended methods (3). The 6-min walking test (6MWT) was performed according to American Thoracic Society guidelines (2), and the quadriceps endurance ( $\left(\mathrm{q} T_{\text {lim }}\right)$ was assessed as previously described (26). The vastus lateralis muscle was biopsied as previously described (26). All evaluations and biopsies were performed at the beginning of exercise training and repeated after $5 \mathrm{wk}(22$ sessions) and $10 \mathrm{wk}$ (14 additional sessions).

Muscle analysis. Muscle biopsies were stored at $-80^{\circ} \mathrm{C}$ until analysis. Cryosections of muscle samples (14 $\mu \mathrm{m}$ thick) were performed for all subjects, for the three training times. Sections were stained using anti-CD31 antibodies (Cat. No. 550389; BD Biosciences), which allowed us to calculate the capillary-to-fiber ratio $(\mathrm{C} / \mathrm{F})$, as previously described (26), on 150 fibers. $\mathrm{NG}^{+}$pericyte coverage was calculated as described elsewhere $(15,23,25,71)$. Briefly, neural/glial antigen 2 (NG2)-positive area (anti-NG2 antibodies; Cat. No. ab83178, Abcam) and platelet endothelial cell adhesion molecule 1 (PECAM1/CD31)positive area were separately subjected to a threshold process, and the ratio of NG2-positive area to CD31-positive area was calculated. For each subject at each time, the $\mathrm{NG}^{+}$pericyte coverage was calculated on a mean of $108 \pm 21$ capillaries. The proportion of pericytes expressing $\alpha$-smooth muscle actin ( $\alpha$ SMA) (anti- $\alpha$ SMA antibodies; Cat. No. ab7817, Abcam) was calculated as the ratio of the number of aSMApositive/NG2-positive pericytes to the total number of NG2-positive pericytes established on an average of $175 \pm 31$ pericytes. All analyses were performed on three randomly chosen regions using ImageJ software under blinded conditions. Further details on muscle analysis are provided in the Supplemental Material.

ECFC/MSC coculture, pericyte culture, and morphologic analysis. For the in vitro analysis, posttraining serums from seven patients with COPD ( 3 from AI and 4 from RI) and seven SHS were tested individually. Human brain vascular pericytes (ScienCell Research Laboratories, Inc.) were exposed to $20 \%$ (vol $/ \mathrm{vol})$ of the SHS or COPD serums described above for $15 \mathrm{~h}$. Cells were fixed and stained with phalloidin (ab176756, Abcam) for elongation analysis, as previously described (37). Images were analyzed with the Shape Descriptors ImageJ plug-in, under blinded conditions, on 40 pericytes/subject, from $\geq 10$ randomly chosen fields. More details about the cell culture and analysis are available in the Supplemental Material. Endothelial colony-forming cells (ECFCs) and MSCs were isolated as previously described (59) and seeded at a 1:1 ratio for 7 days in the presence of $10 \%$ FCS or $20 \%$ $(\mathrm{vol} / \mathrm{vol})$ SHS or COPD serum. ECFCs are isolated from cord blood of healthy individuals. Then, cocultures were fixed and stained with von Willebrand factor (1:500, Dako) or rabbit anti-human calponin (1:100, Abcam) primary antibodies to assess the MSC differentiation into pericytes, as previously described $(6,59)$. At least three randomly chosen fields per condition were analyzed with ImageJ.

Statistical analysis. Characteristics of the two COPD groups and SHS were compared at baseline by one-way analysis of variance or the Kruskal-Wallis test, depending on data normality. Response to exercise training for all variables was analyzed with a linear mixed effect (LME) model fit with the R package nlme, including group effect (G), time effect $(T)$, the interaction between these factors $(G \times T)$ as the 
fixed effect, and the subject effect as the random effect (52). Pearson or Spearman coefficients described the correlations. Data were analyzed with R-3.5.0 software (www.r-project.org) and plotted with GraphPad Prism 5 (GraphPad software). A $P$ value of $<0.05$ was considered significant. More details about statistical analysis and sample size calculation are provided in the Supplemental Material in accordance with American Physiological Society guidelines (41).

More detailed information is available in the Supplemental Material.

\section{RESULTS}

Basal characteristics of patients with COPD and SHS. Clinical and functional baseline characteristics of patients with COPD (AI and RI) and SHS are presented in Table 1. The patients with COPD had mild-to-moderate airway obstruction, and their BODE [body mass index (BMI) (B), degree of obstruction (O), dyspnoea (D), and exercise capacity (E)] index was $\leq 4$. In addition, none of these patients presented a $\mathrm{SpO}_{2}<$ $96 \%$ at rest, indicating the absence of hypoxemia at rest. We found no difference in sex ratio, age, body composition, or physical activity level between the three groups. All subjects were sedentary, as shown by a Voorrips score <9.4 (Table 1). COPD-AI and COPD-RI patients showed significantly lower baseline values of symptom-limited oxygen uptake $\left(\dot{\mathrm{V}}_{2 \mathrm{SL}}\right)$ than SHS (group effect: $P=0.004$, Table 1).

Functional adaptation in response to exercise training. Exercise training was performed at the first ventilatory threshold in seven SHS $\left(50.9 \pm 2.7 \% \dot{V}_{2 S L} ; 13.4 \pm 2.7 \mathrm{~mL} \cdot \mathrm{min}^{-1} \cdot \mathrm{kg}^{-1}\right.$ of $\left.\dot{\mathrm{V}}_{2}\right)$. COPD-AI $(n=7)$ patients were trained at the same absolute intensity as SHS $\left(66.1 \pm 9.8 \% \quad \dot{\mathrm{V}}_{2 \mathrm{SL}} ; 13.4 \pm 2.7\right.$ $\mathrm{mL} \cdot \mathrm{min}^{-1} \cdot \mathrm{kg}^{-1}$ of $\left.\dot{\mathrm{V}}_{2}\right)$. COPD-RI $(n=7)$ patients were trained at the same relative intensity as $\operatorname{SHS}\left(50.9 \pm 2.7 \% \dot{\mathrm{V}}_{2 \mathrm{SL}} ; 9.8 \pm\right.$ $1.9 \mathrm{~mL} \cdot \mathrm{min}^{-1} \cdot \mathrm{kg}^{-1}$ of $\left.\dot{\mathrm{V}}_{2}\right)$. Training intensity was significantly higher in the COPD-AI than in the COPD-RI group $(P=0.002)$. Functional improvements in response to 5 and $10 \mathrm{wk}$ of exercise training in the two patient groups and SHS are presented in Fig. 1. The 6-min walking distance (6MWD) was significantly increased in both patients with COPD and SHS after $10 \mathrm{wk}$ of exercise training $(+5 \pm 7 \%$ for COPD; $+4 \pm 5 \%$ for SHS; Fig. 1 , $A$ and $B$ ) and was not different between the COPD-AI and COPD-RI groups (Fig. $1, A$ and $B$ ). The $T_{\text {lim }}$ response to exercise training was lower in patients with COPD than in SHS $(+77 \% \pm 95 \%$ vs. $+145 \% \pm 167 \%$, respectively; $\mathrm{G} \times \mathrm{T}: P=$ $0.017)$. Oxygen uptake at the ventilatory threshold $\left(\dot{\mathrm{V}}_{\mathrm{O}_{2} \mathrm{VT}}\right)$ was increased only in SHS $(+23 \% \pm 15 \%$ vs. $1 \% \pm 13 \%$ in COPD), with lower values in patients with COPD after 5 and $10 \mathrm{wk}$ of training (Fig. $1 C$ ). $\dot{\mathrm{V}}_{2 \mathrm{SL}}$ was lower in patients with COPD than in SHS (G: $P<0.001$; Fig. $1 D$ ) but increased under exercise training in both patients with COPD and SHS (T: $P=0.029$ ) with no significant difference between the groups (SHS: $8 \% \pm$ $11 \%$ vs. COPD: $4 \% \pm 13 \% ; \mathrm{G} \times \mathrm{T}: P=0.50)$. Both $\dot{\mathrm{V}}_{2 \mathrm{SL}}$ and $\dot{\mathrm{V}} \mathrm{O}_{2 \mathrm{VT}}$ changes and values were similar between COPD-AI and COPD-RI (Fig. 1, $C$ and $D$ ).

Skeletal muscle capillarization and pericyte coverage during training-related angiogenesis. The $\mathrm{C} / \mathrm{F}$ ratio increased under exercise training in both the COPD and SHS groups after 10 wk of training (T: $P<0.001$; Fig. $2 A$ ), with no difference between SHS and COPD $(\mathrm{G} \times \mathrm{T}: P=0.81)$ or COPD-AI and COPD-RI $(\mathrm{G} \times \mathrm{T}: P=0.82)$. Double CD31/NG2 staining of vastus lateralis cryosections from patients with COPD and SHS at each time of training is presented in Fig. $2 B$. As shown in Fig. $2 C$, training induced a significantly different response of $\mathrm{NG}^{+}$ pericyte coverage in patients compared with in SHS $(\mathrm{G} \times \mathrm{T}: P=$ $0.011)$. We observed a significant increase in $\mathrm{NG}_{2}{ }^{+}$pericyte coverage in SHS $(+46.9 \pm 64.2 \%, P=0.013)$ but not in patients with COPD $(+1.38 \pm 57.4 \%, P=0.26)$ from the pretraining $(\mathrm{T} 0)$ to posttraining (T10) biopsies. This difference meant significantly lower $\mathrm{NG}^{+}$pericyte coverage in patients with COPD than in SHS at 5 and 10 wk of exercise training $(P=0.004$ and $P<$ 0.001 , respectively). This result did not differ between the COPDAI or COPD-RI groups (Fig. $2 C$ ). The proportion of $\alpha_{\mathrm{SMA}^{+}}$pericytes increased over time in both groups (Supplemental Figure 1; time effect: $P=0.002$ ), without difference between groups.

In vitro effect of serums on pericyte morphology and MSC differentiation. The effect of COPD and SHS serum on pericyte cytoskeleton morphology was assessed first (Fig. 3). COPD serum induced significantly greater pericyte elongation than SHS serum (Fig. 3, $A$ and $B ; P<0.001$ ), without pericyte area alteration (Fig. $3 C ; P=0.55$ ).

We and others have demonstrated that MSCs can differentiate into pericytes in contact with ECFCs in vitro and in vivo (59).

Table 1. Baseline clinical and functional characteristics of COPD-AI and COPD-RI groups and SHS

\begin{tabular}{|c|c|c|c|c|}
\hline & SHS & COPD-AI & COPD-RI & $\begin{array}{l}\text { ANOVA } \\
(P \text { value })\end{array}$ \\
\hline Subjects, $n$ & 7 & 7 & 7 & \\
\hline Sex, male/female & $4 / 3$ & $4 / 3$ & $4 / 3$ & \\
\hline Age, yr & $63.3 \pm 5.8$ & $64.0 \pm 4.3$ & $67.0 \pm 5.7$ & 0.40 \\
\hline $\mathrm{FEV}_{1}, \%$ Pred & $109.9 \pm 16.9$ & $70.7 \pm 20.4^{* k_{k} \cdot k}$ & $78.6 \pm 17.6^{* * *}$ & $<0.01$ \\
\hline $\mathrm{FEV}_{1} / \mathrm{VC}, \%$ Pred & $74.1 \pm 4.0$ & $59.3 \pm 13.5^{*}$ & $57.6 \pm 10.3^{* *}$ & $<0.01$ \\
\hline $\mathrm{BMI}, \mathrm{kg} / \mathrm{m}^{2}$ & $26.4 \pm 3.2$ & $24.9 \pm 3.6$ & $27.5 \pm 4.0$ & 0.40 \\
\hline FFMI, $\mathrm{kg} / \mathrm{m}^{2}$ & $18.6 \pm 2.1$ & $17.7 \pm 3.2$ & $19.4 \pm 3.4$ & 0.59 \\
\hline PA level, Voorrips score & $2.9(2.1-9.2)$ & $4.8(2.8-10.7)$ & $5.7(2.9-9.9)$ & 0.51 \\
\hline qMVC, $\mathrm{kg}$ & $45.8 \pm 10.9$ & $41.0 \pm 15.4$ & $37.7 \pm 13.8$ & 0.54 \\
\hline 6 MWD. \%Pred & $109.0 \pm 8.2$ & $95.6 \pm 13.5$ & $99.4 \pm 10.6$ & 0.09 \\
\hline$\dot{\mathrm{V}}_{2 \mathrm{SL}}, \%$ Pred & $111.9 \pm 15.6$ & $83.4 \pm 15.8^{* *}$ & $84.3 \pm 14.7^{* *}$ & $<0.01$ \\
\hline$\dot{\mathrm{V}} \mathrm{O}_{2 \mathrm{VT}}, \% \dot{\mathrm{V}} \mathrm{O}_{2 \max \text { pred }}$ & $57.1 \pm 8.7$ & $51.6 \pm 8.8$ & $49.3 \pm 6.2$ & 0.22 \\
\hline$T_{\text {lim }}, \mathrm{s}$ & $599 \pm 268$ & $434 \pm 207$ & $484 \pm 257$ & 0.45 \\
\hline
\end{tabular}

Data are presented as means \pm SD or median (Q1-Q3). \% pred., \% predicted; 6MWD, 6-min walking distance; BMI, body mass index; FFMI, fat-free mass index; $\mathrm{FEV}_{1}$, forced expiratory volume in $1 \mathrm{~s}$; PA, physical activity; Post hoc test, ${ }^{*} P<0.05, * * P<0.01$, $* * P<0.001$; qMVC, quadriceps maximal voluntary contraction; $T_{\text {lim }}$, endurance time of quadriceps; $\dot{\mathrm{V}}_{2 \mathrm{SL}}$, symptom-limited oxygen uptake; $\mathrm{VC}$, slow vital capacity; $\dot{\mathrm{V}}_{2 \mathrm{VT}}$, oxygen uptake at ventilatory threshold. 

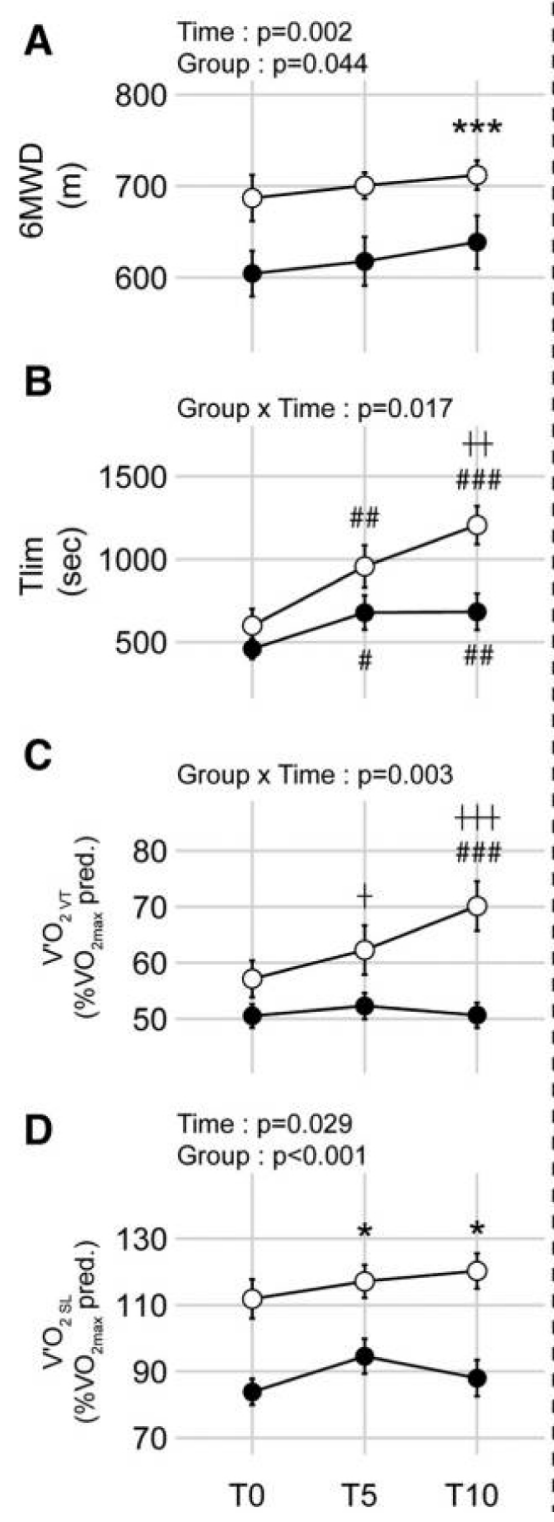

Time : $p=0.004$

Group : $p=0.74$

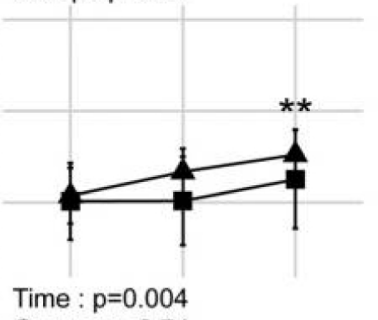

Group : $p=0.74$

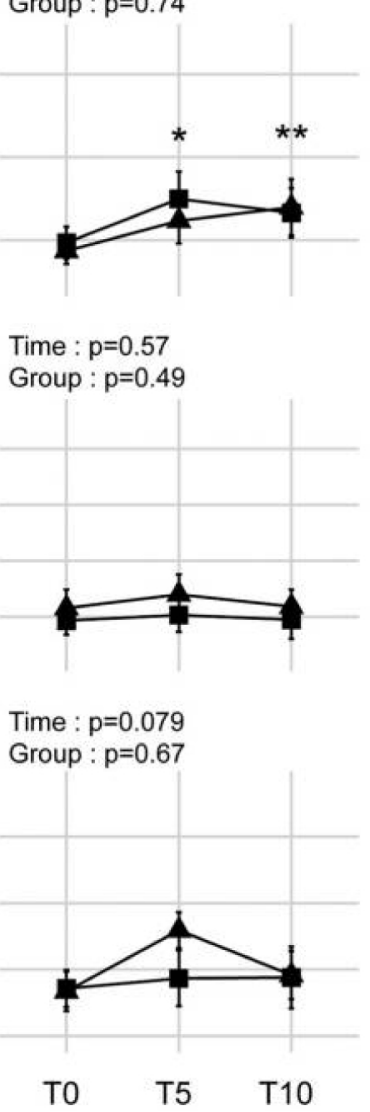

Fig. 1. Functional adaptations to exercise training in COPD-AI and COPD-RI patients and sedentary healthy subjects (SHS). $A-D$ : variations in functional parameters between pretraining (T0) and after $5 \mathrm{wk}$ (T5) and $10 \mathrm{wk}(\mathrm{T} 10)$ in COPD $(n=14)$ and SHS ( $n=$ $7)$ on the left part and COPD-AI $(n=7)$ and COPD-RI $(n=7)$. A: six-minute walking distance (6MWD). $B$ : endurance time of quadriceps $\left(T_{\mathrm{lim}}\right) . C$ : oxygen uptake at the ventilatory threshold $\left(\dot{\mathrm{V}}_{2 \mathrm{VT}}\right)$. $D$ : symptom-limited oxygen uptake $\left(\dot{\mathrm{V}}_{2} \mathrm{SL}\right)$. Data are presented as means \pm SE. Linear mixed effect model: Time: time effect; Group: group effect; Group $\times$ Time: group/ time interaction. Post hoc test: different from T0 in both groups (time effect): $* P<0.05$, $* * P<0.01$, $* * * P<0.001$. Different from T0 in isogroup: $\# P<$ $0.05, \# \# P<0.01, \# \#+P<0.001$. Different from the other group at isotime: ${ }^{+} P<0.05, \mathrm{H}_{P}<0.01, \mathrm{H}_{P}$ $<0.001$. COPD-AI, chronic obstructive pulmonary disease patients in absolute intensity; COPD-RI, chronic obstructive pulmonary disease patients in relative intensity.
We tested the in vitro effect of COPD and SHS serum on ECFC/MSC cocultures. The cocultures were exposed to human serum for $1 \mathrm{wk}$, and fetal calf serum (FCS) was used as a positive control. In the cocultures exposed to both FCS and SHS serum, we observed a broad expression of calponin, a valid marker of pericytes (6), in MSCs after 1 wk (Supplemental Figure 2; Fig. 4A, first line). Conversely, calponin expression in MSCs was significantly reduced in the COPD serum compared with in the SHS serum after 1 wk of coculture $(P<0.001$; Fig. $4 B)$. The positive stain for von Willebrand factor on the ECFCs in cocultures treated with COPD serum confirmed that this result was not due to the loss of ECFCs but was serum dependent (Fig. 4A). We found a significant positive correlation between calponin expression in MSCs and the pericyte coverage of muscle capillaries in the subjects from whom the serum originated $(r=0.74, P=0.003$; Fig. $4 C)$.

\section{O $\operatorname{SHS}(n=7)$ \\ - $\operatorname{COPD}(n=14)$ \\ $\Delta$ COPD Al $(n=7)$ \\ COPD RI $(n=7)$}

\section{DISCUSSION}

In a context of altered improvements in muscle endurance and $\dot{\mathrm{V}}_{\mathrm{O}_{2 \mathrm{SL}}}$, we observed that the pericyte coverage of muscle capillaries was blunted in patients with COPD. This pericyte defect occurred regardless of training intensity or duration and may have been consecutive to the deleterious effects of COPD circulating factors.

After 10 wk of exercise training, both patients with COPD and SHS showed improved functional capacities, with significantly increased $6 \mathrm{MWD}, T_{\mathrm{lim}}$, and $\dot{\mathrm{V}}_{2 \mathrm{SL}}$ (Fig. 1). The training response of $\dot{\mathrm{V}}_{\mathrm{O}_{2 S L}}$ did not differ between patients with COPD and SHS, but this may have resulted from a ceiling effect in our SHS [with a baseline $\dot{\mathrm{V}}_{2 \mathrm{SL}}>100 \%$ pred. and a $\dot{\mathrm{V}}_{\mathrm{O}_{2 S L}}$ gain less than in the previous study (26)]. Indeed, even after 10 wk of training at the same absolute intensity as SHS, patients with COPD failed to display benefits in the local endurance capacity 


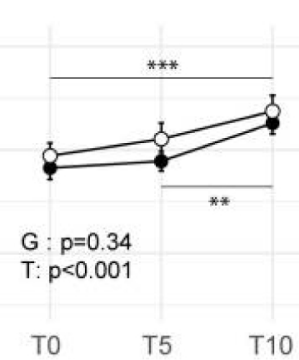

i

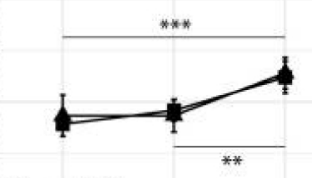

$G: p=0.92$
$T: p=0.001$

$\begin{array}{llll}\text { T10 T0 } & \text { T5 } & \text { T10 }\end{array}$

- $\operatorname{SHS}(n=7)$

- $\operatorname{COPD}(n=14)$

$\triangle \operatorname{COPD}$ Al $(n=7)$

- COPD RI (n=7)

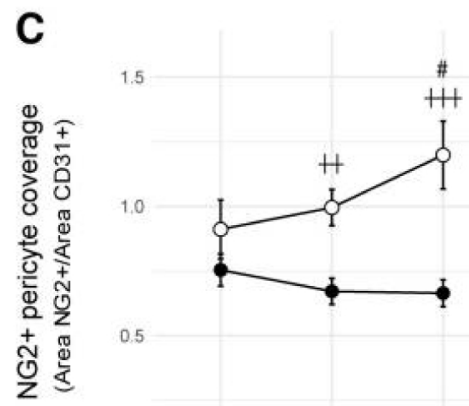

0.0 GXT: $p=0.011$

T0 T5 T10
B
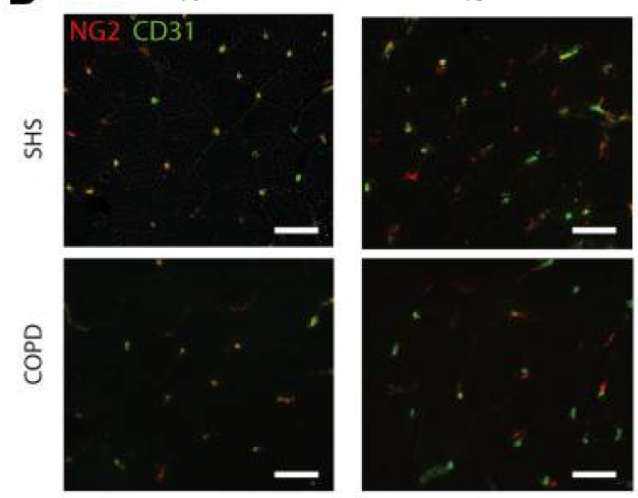

D
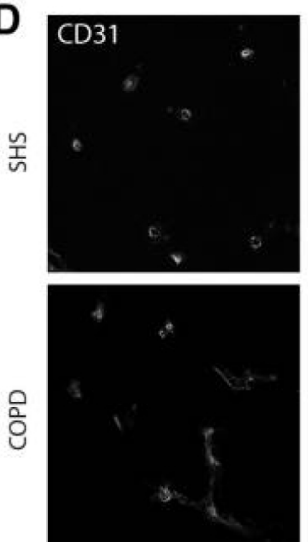
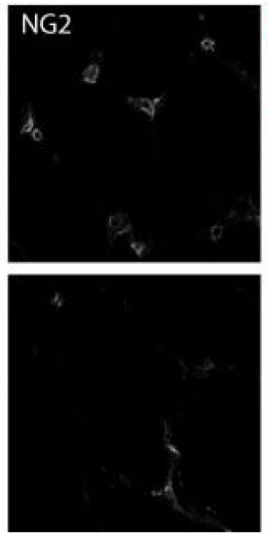

T10
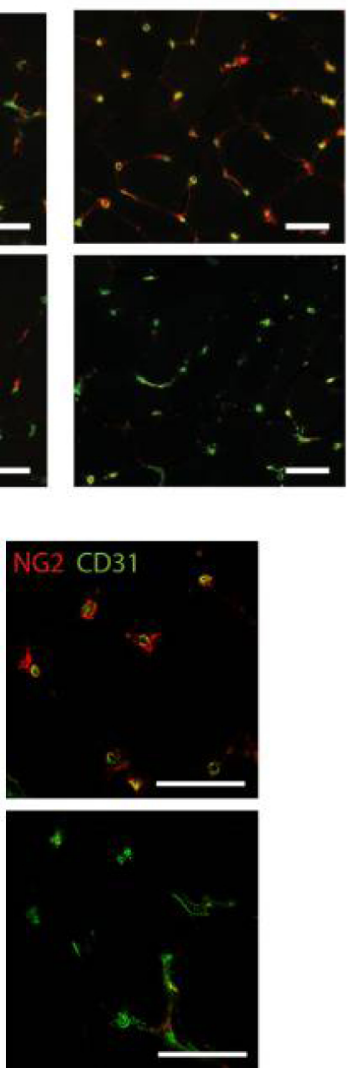

Fig. 2. Capillary and $\mathrm{NG}^{+}$pericyte coverage changes in patients with COPD and sedentary healthy subjects (SHS) in response to exercise training. $A$ and $C$ : pretraining (T0) and 5-wk (T5) and 10-wk (T10) exercise training values of vastus lateralis skeletal muscle capillarization $(A)$ and NG2 ${ }^{+}$pericyte coverage $(C)$ for both SHS and COPD-AI and COPD-RI. A: capillary-to-fiber (C/F) ratio. B: CD31/NG2 immunofluorescent double-staining images of vastus lateralis cryosection of patients with COPD and SHS at baseline (T0) and after $5 \mathrm{wk}$ (T5) and $10 \mathrm{wk}$ (T10) of exercise training. $D$ : higher magnification CD31/NG2 immunofluorescent double-staining images with split channels for SHS and patients with COPD at T10. Data are presented as means \pm SE. Post hoc test: different from T0 in both groups (time effect): ${ }^{* * P}<0.01, * * * P<0.001$. Different from T0 in isogroup: $\# P<0.05$. Different from the other group at isotime: $\uplus_{P}<0.01, H+P<0.001$. Scale bar: $50 \mu \mathrm{m}$. COPD-AI, chronic obstructive pulmonary disease patients in absolute intensity; COPD-RI, chronic obstructive pulmonary disease patients in relative intensity.

of muscle ( $T_{\text {lim }}$ ) equal to those in SHS (Fig. $1 B$ ). Endurance is determined by both diffusive and convective $\mathrm{O}_{2}$ transports (21). Similarly, submaximal $\dot{\mathrm{V}}_{\mathrm{O}_{2 \mathrm{~V}}}$ improved less in patients with COPD than in SHS (Fig. 1C). Compared with $\dot{\mathrm{V}}_{2 \mathrm{SL}}$, $\dot{\mathrm{V}}_{2 \mathrm{VT}}$ is more closely related to the muscle oxygen uptake capacities (34). Lower responses to training were observed in both the COPD-AI and COPD-RI groups and at both T5 and T10, suggesting that the increase in training intensity (from 51\% to 66\% of $\dot{\mathrm{V}}_{2 \mathrm{SL}}$ ) or duration (from 5 to $10 \mathrm{wk}$ ) did not restore a physiological response in the patients. The randomized, controlled double-blind design to assign patients with COPD to exercise intensity groups (AI or RI) increased the validity of these results. Thus, the blunted functional response to exercise training in patients with COPD may be more related to an intrinsic muscle impairment than to an inappropriate training modality.

In previous studies, the impaired functional adaptations to exercise training in patients with COPD were associated with blunted capillary creation (26). Conversely to this finding, we observed no blunted creation of new vessels in these patients compared with in SHS, possibly because the patients in the present study differed in disease severity from those of the earlier study $\left(\mathrm{FEV}_{1}: 75 \pm 19\right.$ vs. $45.6 \pm 17.5 \%$ pred.) (26). Hypoxemia might explain this result, as Costes et al. (17) reported an increase in the $\mathrm{C} / \mathrm{F}$ ratio in response to exercise training only in nonhypoxemic patients. Given that none of our patients with COPD presented $\mathrm{SpO}_{2}<92 \%$ at rest [whereas $50 \%$ of the patients in the previous study (26) had $\mathrm{SpO}_{2}<92 \%$ at rest], it may be that capillary creation is preserved in less severe and normoxic patients with COPD. This preserved capillary creation is not discrepant with impaired pericyte coverage. Indeed, capillary regression was shown to occur later than pericyte loss during disease progression (9). Thus, in our patients with mild-tomoderate COPD, the impaired pericyte coverage might have been associated with preserved capillarization, whereas impaired capillary creation and coverage would have occurred in more severe patients.

To assess the pericyte coverage of skeletal muscle capillaries from muscle samples, most studies have used NG2/CD31 double-staining on transversal sections of muscle and calculated the ratio for the two areas of staining $(9,15,23,25,71)$. Using this methodology, we found that exercise training increased the pericyte coverage after $10 \mathrm{wk}$ in the SHS group but not in the patients with COPD (Fig. 2, $B$ and $C$ ). The increase that we found in SHS was consistent with the study by Baum et al. (4), which showed an increase in pericyte coverage of skeletal muscle capillaries after 8 wk of exercise training in healthy humans. 


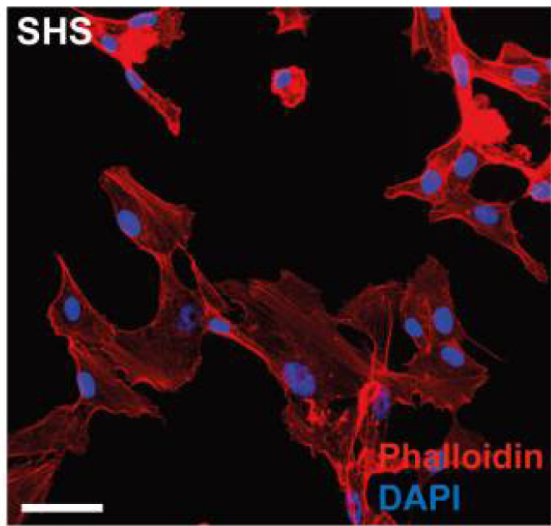

B

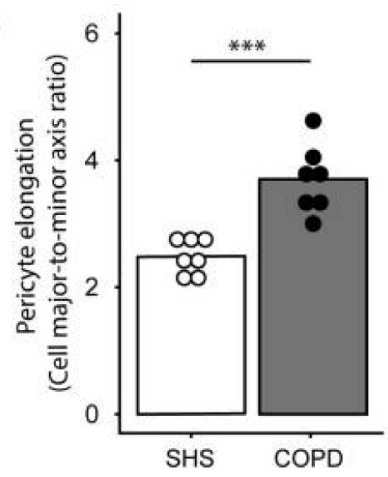

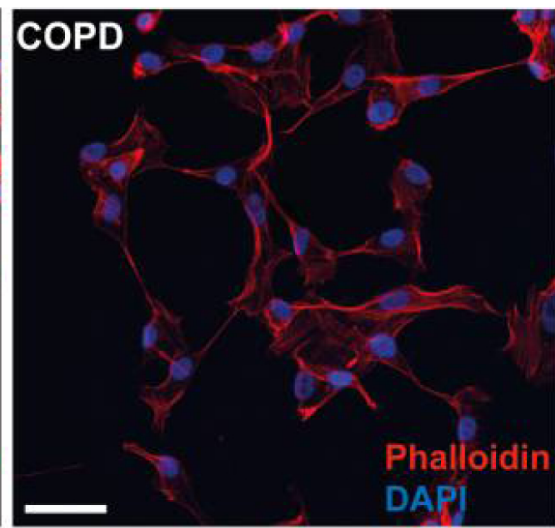

C

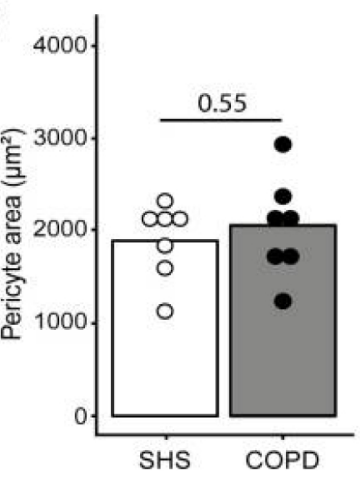

Fig. 3. Effect of posttraining serum from patients with COPD and SHS on pericyte morphology. A: representative image of pericytes exposed to COPD patient or SHS serum. F-actin was stained with phalloidin and nucleus with DAPI. $B$ : pericyte elongation and area $(C)$ after exposure to $20 \%$ (vol/vol) serum from patients with COPD or SHS posttraining for $15 \mathrm{~h}$. Data are presented as means and individual points. Linear mixed effect model: $* * * P<0.001$. COPD-AI, chronic obstructive pulmonary disease patients in absolute intensity; COPDRI, chronic obstructive pulmonary disease patients in relative intensity; SHS, sedentary healthy subjects.
Conversely, Egginton et al. (20) found reduced pericyte coverage of muscle capillaries after muscle stimulation. However, this study was conducted only through electrical stimulation in rats, which does not fully represent exercise training, and for only 3-7 days. The angiogenic process was found to begin with a destabilization phase with pericyte detachment, followed by a maturation phase with pericyte recruitment (10). The first phase occurred during the first weeks of training, and the second appeared later, at around 4-6 wk (27). Thus, we expected an increase in pericyte coverage in our subjects, as the study by Baum et al. (4) used actual exercise training in humans with a timing that was closer to ours. The finding that pericyte coverage failed to increase in our patients with COPD thus appears to be a novel pathological feature of the misadaptation to training in their skeletal muscle circulation and may have clinical repercussions.

During proangiogenic interventions, an increase in pericyte coverage together with an increased number of skeletal muscle capillaries has been associated with a greater increase in muscle perfusion $(13,14,42,57)$, which is a major determinant of oxygen uptake capacity (56). Evidence is accumulating that pericyte coverage is involved in the regulation of local capillary blood flow $(28,36,38,43)$, especially in skeletal muscle $(29$, 46,63 ), which is a determinant in $\mathrm{O}_{2}$ supply and muscle $\dot{\mathrm{V}}_{2}$ (62). This vasoactive role is mainly dependent on aSMA expression (1), and we consistently found a high proportion of pericytes that were $\alpha \mathrm{SMA}^{+}$in both patients with COPD and SHS (Supplemental Figure 2). Interestingly, the proportion of $\alpha \mathrm{SMA}^{+} / \alpha \mathrm{SMA}^{-}$was preserved in patients with $\mathrm{COPD}$, suggesting that the pericyte loss in these patients affected both contractile and noncontractile pericytes (Supplemental Figure 2). Although we found that the adaptations in capillary number were not impaired in our patients with COPD (Fig. 2A), we hypothesize that the blunted pericyte coverage in capillaries has a role in the defective adaptation of muscle endurance and submaximal $\dot{\mathrm{V}}_{2}$ in these patients. Future studies with local muscle blood flow assessment and/or pericyte loss in animal models during traininginduced angiogenesis will address this hypothesis of a causal relationship between pericyte coverage and muscle convective $\mathrm{O}_{2}$ supply.

A body of evidence now points to the deleterious effect of COPD on pericytes. Indeed, pericyte debris has been found in the endoneural capillaries of patients with COPD (67). Moreover, the pericyte coverage regulates the capillary permeability, and a defective pericyte coverage leads to capillary leakages (30). Consistently, microalbuminuria and cerebral microbleeds have been found in these patients $(11,40)$. Lastly, during traininginduced angiogenesis, we found ultrastructural evidence of disturbed endothelium/pericyte interactions in patients with COPD in an earlier study (5), as well as a smaller increase in pericyte coverage in the present study (Fig. 2C). On the other hand, we observed a proatrophic effect of COPD patient serum in human myotubes in vitro (12), which argues for a role of the COPD circulating microenvironment in muscle impairment. Nevertheless, the current study is the first to provide experimental evidence of a direct effect of COPD serum on pericytes, suggesting a systemic effect of deleterious circulating factors, possibly due to inflammation. Indeed, lipopolysaccharide injection, a trigger of systemic inflammation, is known to induce pericyte loss (22), and basal levels of inflammation are increased in COPD patient serum (53). In the present study, isolating the culprit(s) would have required wide cytokine screening plus other experiments (testing cytokine agonists/antagonists on pericytes), necessitating a large quantity of serum that we unfortunately did not have access to. 

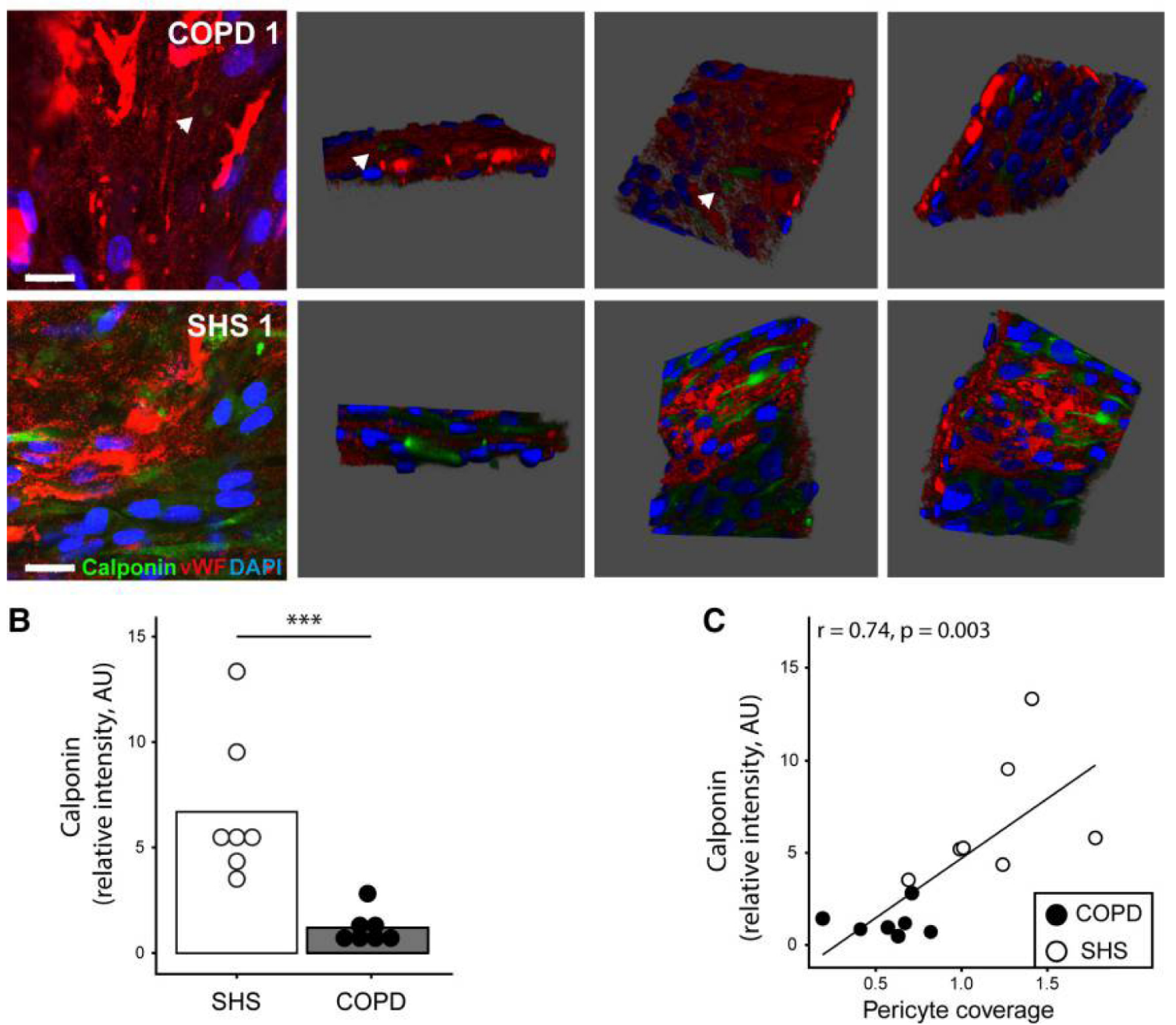

Fig. 4. Calponin expression in MSCs from MSC/ECFC coculture exposed to post-training serum from patients with COPD and SHS. $A$ : representative image of MSC/ECFC coculture exposed to COPD or SHS serum. B: quantification of calponin fluorescence intensity in coculture images after exposure to 20\% (vol/vol) COPD or SHS posttraining serum for 5 days. $C$ : relation between in vitro calponin fluorescence intensity in response to posttraining serum and in vivo posttraining pericyte coverage of skeletal muscle capillaries. Data are presented as means and individual points. Linear mixed effect model: $* * * P<0.001 . \mathrm{COPD}$, chronic obstructive pulmonary disease; ECFC, endothelial colony-forming cell; MSC, mesenchymal stem cell; SHS, sedentary healthy subjects.

Thus, addressing this question will require a specifically designed study. We did, however, focus on the mechanisms that might explain the lack of pericyte coverage. We first tested the hypothesis that circulatory factors of COPD can induce changes in pericyte elongation. We observed that, compared with posttraining SHS serum, posttraining COPD serum induced greater pericyte elongation (Fig. 4), which was assessed by shape description based on phalloidin staining, as previously described $(37,50)$. Few studies described the pericyte elongation as a marker of pericyte migratory phenotype leading to pericyte loss $(50,51)$. This possible promigratory effect of the COPD serum on pericytes will have to be confirmed in future studies. For this experiment, we have used human brain and not skeletal muscle pericytes. Yet, the serum effect on human brain pericytes was clear and the skeletal muscle pericytes share most of the brain pericyte properties (47). We then tested whether the effect of COPD serum would also disturb the de novo recruitment of pericytes during the angiogenic process. This recruitment is dependent on MSC differentiation into pericytes $(19,31)$, which requires endothelial/MSC heterotypic cell contacts (32). MSC differentiation into pericytes is usually tested by assessing the calponin expression in the MSCs of MSC/endothelial cells or endothelial colony-forming cell cocultures $(59,60)$, and we found that it was dramatically reduced in the COPD serum condition (Fig. $4 B$ ). With these experiments, we provide evidence of the deleterious effect of COPD circulating factors on pericyte morphology and differentiation. Nevertheless, the COPD mechanisms suggested by our in vitro analysis should be verified in vivo in future studies during training-induced angiogenesis. As a perspective for future research, the involvement of inflammation-dependent impairment in Cx43-dependent gap junctions and/or Notch3/Jagged-1 interactions might be investigated, as previously shown $(22,32,39,61)$. The tumor necrosis factor (TNF)- $\alpha$ decreases the Cx43 expression in endothelial cells (68), whereas the interleukin (IL)-1 $\beta$ decreases both Notch3 and Jagged- 1 expressions (16). Because both IL-1 $\beta$ and TNF- $\alpha$ 
levels are increased in the serum of patients with COPD (54), they constitute good candidates for the pericyte impairment in COPD. Then, antagonization of these specific targets (e.g., with anti-TNF $\alpha$ ) would constitute a strategy to limit the pericyte impairment in patients with COPD. Another possibility would be to test the effect of a pharmacological agent known to enhance the skeletal muscle pericyte coverage [angiopoietin 1 (57) or PDGF-BB (24)] in vivo in a COPD animal model.

Perspective. It is now well admitted that patients with COPD present a heterogeneous response of skeletal muscle to exercise training (45). Currently, understanding the cause of this heterogeneous response has become a major issue for researchers in the field of pulmonary rehabilitation. Indeed, it has been shown in patients with COPD that the functional benefits of training are directly related to the patient's quality of life and prognosis (8). Therefore, in the context of a blunted functional adaptation to exercise training, showing a novel and relevant pathway, i.e., the defect of capillary pericyte coverage, may have substantial clinical implications. As previously discussed, the pericytes have a potential role in muscle $\mathrm{O}_{2}$ supply. In addition, pericytes are also critical for the capillary maturation during angiogenesis. Indeed, it has been shown that a defective pericyte coverage leads to nonviable and dysfunctional capillaries $(30,35)$. Lastly, the pericytes have been also implicated in the skeletal muscle growth and regeneration (18), and impairments in pericyte coverage can limit skeletal muscle adaptation to training (48). These relations linking the pericyte defect and the impairment of the training-induced functional benefits constitute a clinical rationale for targeting the skeletal muscle pericytes in COPD during training in preclinical in vitro or in vivo studies.

Limitations. The authors acknowledge some limitations of this study. First, because of the design of the study and of the three muscle biopsies, the sample size was small and could limit the generalization of the observations. However, the sample size was predetermined and based on an expected effect size for the muscle capillarization. Second, there is a limitation related to the method to assess the pericyte coverage of capillaries, and the platelet-derived growth factor receptor (PDGFR)- $\beta$ could have been used. Yet, there is no marker able to identify specifically all the populations of pericytes (65). We used NG2 because it is a valid and specific marker of pericytes during angiogenesis $(49,66)$. If this marker has previously been used to identify a loss of pericyte coverage and its consequences in the skeletal muscle $(9,15,23,25,71)$, our results for the $\mathrm{NG}^{+}$pericyte subset should be extrapolated for PDGFR- $\beta^{+}$or any other population of pericytes with caution. Lastly, the pericyte coverage was assessed by immunostaining as described and validated before $(9,15,23,25,71)$. In contrast to electron microscopy, this method does not assess the contact length between endothelial cells and pericytes and does not make the distinction between pericytes that are adjacent or contiguous to the capillaries. Yet, it allows the assessment of the pericyte coverage of hundreds of capillaries per subject, providing a global index of pericyte coverage.

Conclusion. In response to exercise training, patients with $\mathrm{COPD}$ showed blunted muscle endurance and $\dot{\mathrm{V}}_{2}$ improvements compared with age- and sex-matched SHS. Moreover, despite preserved capillary creation, patients with COPD showed an impaired increase in pericyte coverage. These impairments constitute an early event in the disease time course. This study also presents the first evidence of a causal deleterious effect of
COPD on pericytes through serum circulating factors. We hypothesize that a misadaptation of pericyte coverage potentially impacts the muscle oxygen supply, which along with circulating therapeutic targets should be considered as a clinically relevant issue to be specifically addressed in future studies.

\section{ACKNOWLEDGMENTS}

We thank C. Stott for critical reading of the manuscript.

\section{DISCLOSURES}

F.G. reports grants from SOS Oxygene, Agir à Dom', and Bastide Medical, outside the submitted work. All other authors have nothing to disclose.

\section{AUTHOR CONTRIBUTIONS}

L.B., J.M., M.H., F.G., P.P., E.R., A.B., and M.B. conceived and designed research; L.B., F.G., P.P., E.R., M.C., A.B., E.P., M.B., and B.A. performed experiments; L.B., D.M.S., M.H., F.G., P.P., E.R., M.C., A.B., E.P., M.B., B.A., and N.M. analyzed data; L.B., A.P., N.M., D.M.S., M.H., F.G., P.P., E.R., M.C., A.B., M.B., and N.M. interpreted results of experiments; L.B. prepared figures; L.B. drafted manuscript; L.B., A.P., N.M., D.M.S., M.H., F.G., P.P., E.R., and A.B. edited and revised manuscript; L.B., J.M., A.P., N.M., D.M.S., M.H., F.G., P.P., E.R., M.C., A.B., E.P., M.B., B.A., and N.M. approved final version of manuscript.

\section{REFERENCES}

1. Alarcon-Martinez L, Yilmaz-Ozcan S, Yemisci M, Schallek J, Kılıç K, Can A, Di Polo A, Dalkara T. Capillary pericytes express $\alpha$-smooth muscle actin, which requires prevention of filamentous-actin depolymerization for detection. elife 7: e34861, 2018. [Erratum in elife 7: 10.7554/ eLife.348618] doi:10.7554/eLife.34861.

2. ATS Committee on Proficiency Standards for Clinical Pulmonary Function Laboratories. ATS statement: guidelines for the six-minute walk test. Am J Respir Crit Care Med 166: 111-117, 2002. doi:10.1164/ ajrecm.166.1.at1102.

3. American Thoracic Society; American College of Chest Physicians. ATS/ACCP Statement on cardiopulmonary exercise testing. Am J Respir Crit Care Med 167: 211-277, 2003. doi:10.1164/rccm.167.2.211.

4. Baum O, Gübeli J, Frese S, Torchetti E, Malik C, Odriozola A, Graber F, Hoppeler H, Tschanz SA. Angiogenesis-related ultrastructural changes to capillaries in human skeletal muscle in response to endurance exercise. $J$ Appl Physiol (1985) 119: 1118-1126, 2015. doi:10.1152/japplphysiol.00594. 2015.

5. Blervaque L, Passerieux E, Pomiès $P$, Catteau M, Héraud N, Blaquière M, Bughin F, Ayoub B, Molinari N, Cristol J-P, Perez-Martin A, Mercier J, Hayot M, Gouzi F. Impaired training-induced angiogenesis process with loss of pericyte-endothelium interactions is associated with an abnormal capillary remodelling in the skeletal muscle of COPD patients. Respir Res 20: 278, 2019. doi:10.1186/s12931-019-1240-6.

6. Boscolo E, Stewart CL, Greenberger S, Wu JK, Durham JT, Herman IM, Mulliken JB, Kitajewski J, Bischoff J. JAGGED1 signaling regulates hemangioma stem cell-to-pericyte/vascular smooth muscle cell differentiation. Arterioscler Thromb Vasc Biol 31: 2181-2192, 2011. doi:10.1161/ATVBAHA.111.232934.

7. Broxterman RM, Hoff J, Wagner PD, Richardson RS. Determinants of the diminished exercise capacity in patients with chronic obstructive pulmonary disease: looking beyond the lungs. $J$ Physiol 598: 599-610, 2020. doi:10.1113/JP279135.

8. Camillo CA, Langer D, Osadnik CR, Pancini L, Demeyer H, Burtin C, Gosselink R, Decramer M, Janssens W, Troosters T. Survival after pulmonary rehabilitation in patients with COPD: impact of functional exercise capacity and its changes. Int J Chron Obstruct Pulmon Dis 11: 2671-2679, 2016. doi:10.2147/COPD.S113450.

9. Caporali A, Meloni M, Nailor A, Mitić T, Shantikumar S, Riu F, SalaNewby GB, Rose L, Besnier M, Katare R, Voellenkle C, Verkade P, Martelli F, Madeddu P, Emanueli C. p75(NTR)-dependent activation of $\mathrm{NF}-\mathrm{\kappa B}$ regulates microRNA-503 transcription and pericyte-endothelial crosstalk in diabetes after limb ischaemia. Nat Commun 6: 8024, 2015. doi:10.1038/ncomms9024. 
10. Carmeliet P, Jain RK. Molecular mechanisms and clinical applications of angiogenesis. Nature 473: 298-307, 2011. doi:10.1038/nature10144.

11. Casanova C, de Torres JP, Navarro J, Aguirre-Jaíme A, Toledo P, Cordoba E, Baz R, Celli BR. Microalbuminuria and hypoxemia in patients with chronic obstructive pulmonary disease. Am J Respir Crit Care Med 182: 1004-1010, 2010. [Erratum in Am J Respir Crit Care Med. 82(8):1004-1010, 2010] doi:10.1164/rccm.201003-0360OC

12. Catteau M, Gouzi F, Blervaque L, Passerieux E, Blaquière M, Ayoub B, Bughin F, Mercier J, Hayot M, Pomiès P. Effects of a human microenvironment on the differentiation of human myoblasts. Biochem Biophys Res Commun 525: 968-973, 2020. doi:10.1016/j.bbrc.2020.03.020.

13. Chen F, Liu Q, Zhang ZD, Zhu XH. Co-delivery of G-CSF and EPO released from fibrin gel for therapeutic neovascularization in rat hindlimb ischemia model. Microcirculation 20: 416-424, 2013. doi:10.1111/ micc. 12037.

14. Chen L, Wang L, Li Y, Wuang L, Liu Y, Pang N, Luo Y, He J, Zhang $\mathbf{L}, \mathbf{C h e n} \mathbf{N}, \mathbf{L i} \mathbf{R}, \mathbf{W u} \mathbf{J}$. Transplantation of normal adipose tissue improves blood flow and reduces inflammation in high fat fed mice with hindlimb ischemia. Front Physiol 9: 197, 2018. [Erratum in Front. Physiol. 9:717: 10.3389/fphys.2018.00717] doi:10.3389/fphys.2018.00197.

15. Chintalgattu V, Rees ML, Culver JC, Goel A, Jiffar T, Zhang J, Dunner K, Pati S, Bankson JA, Pasqualini R, Arap W, Bryan NS, Taegtmeyer H, Langley RR, Yao H, Kupferman ME, Entman ML, Dickinson ME, Khakoo AY. Coronary microvascular pericytes are the cellular target of sunitinib malate-induced cardiotoxicity. Sci Transl Med 5 187ra69-187ra69, 2013. doi:10.1126/scitranslmed.3005066.

16. Clément N, Gueguen M, Glorian M, Blaise R, Andréani M, Brou C Bausero P, Limon I. Notch3 and IL-1beta exert opposing effects on a vascular smooth muscle cell inflammatory pathway in which NF-kappaB drives crosstalk. J Cell Sci 120: 3352-3361, 2007. doi:10.1242/jcs.007872.

17. Costes F, Gosker H, Feasson L, Desgeorges M, Kelders M, Castells J, Schols A, Freyssenet D. Impaired exercise training-induced muscle fiber hypertrophy and Akt/mTOR pathway activation in hypoxemic patients with COPD. J Appl Physiol (1985) 118: 1040-1049, 2015. doi:10.1152/ japplphysiol.00557.2014.

18. Dellavalle A, Maroli G, Covarello D, Azzoni E, Innocenzi A, Perani L, Antonini S, Sambasivan R, Brunelli S, Tajbakhsh S, Cossu G. Pericytes resident in postnatal skeletal muscle differentiate into muscle fibres and generate satellite cells. Nat Commun 2: 499, 2011. doi:10.1038/ncomms1508.

19. Dhar K, Dhar G, Majumder M, Haque I, Mehta S, Van Veldhuizen PJ, Banerjee SK, Banerjee S. Tumor cell-derived PDGF-B potentiates mouse mesenchymal stem cells-pericytes transition and recruitment through an interaction with NRP-1. Mol Cancer 9: 209, 2010. doi:10.1186/1476-45989-209.

20. Egginton S, Hudlicka O, Brown MD, Graciotti L, Granata AL. In vivo pericyte-endothelial cell interaction during angiogenesis in adult cardiac and skeletal muscle. Microvasc Res 51: 213-228, 1996. doi:10.1006/ mvre.1996.0022.

21. Esposito F, Mathieu-Costello O, Shabetai R, Wagner PD, Richardson RS. Limited maximal exercise capacity in patients with chronic heart failure: partitioning the contributors. J Am Coll Cardiol 55: 1945-1954, 2010. doi:10.1016/j.jacc.2009.11.086.

22. Fernandez-Cobo M, Gingalewski C, Drujan D, De Maio A. Downregulation of connexin 43 gene expression in rat heart during inflammation. The role of tumour necrosis factor. Cytokine 11: 216-224, 1999. doi:10.1006/ cyto. 1998.0422.

23. Fukada K, Kajiya K. Age-related structural alterations of skeletal muscles and associated capillaries. 23: 79-82, 2020. doi:10.1007/s10456-02009705-1.

24. Gianni-Barrera R, Burger M, Wolff T, Heberer M, Schaefer DJ, Gürke L, Mujagic E, Banfi A. Long-term safety and stability of angiogenesis induced by balanced single-vector co-expression of PDGF-BB and VEGF164 in skeletal muscle. Sci Rep 6: 21546, 2016. doi:10.1038/ srep21546.

25. Gianni-Barrera R, Butschkau A, Uccelli A, Certelli A, Valente P, Bartolomeo M, Groppa E, Burger MG, Hlushchuk R, Heberer M, Schaefer DJ, Gürke L, Djonov V, Vollmar B, Banfi A. PDGF-BB regulates splitting angiogenesis in skeletal muscle by limiting VEGF-induced endothelial proliferation. Angiogenesis 21: 883-900, 2018. doi:10.1007/ s10456-018-9634-5.

26. Gouzi F, Préfaut C, Abdellaoui A, Roudier E, de Rigal P, Molinari N, Laoudj-Chenivesse D, Mercier J, Birot O, Hayot M. Blunted muscle angiogenic training-response in COPD patients versus sedentary controls. Eur Respir J 41: 806-814, 2013. doi:10.1183/09031936.00053512.
27. Haas TL, Nwadozi E. Regulation of skeletal muscle capillary growth in exercise and disease. Appl Physiol Nutr Metab 40: 1221-1232, 2015. doi:10.1139/apnm-2015-0336.

28. Hall CN, Reynell C, Gesslein B, Hamilton NB, Mishra A, Sutherland BA, O'Farrell FM, Buchan AM, Lauritzen M, Attwell D. Capillary pericytes regulate cerebral blood flow in health and disease. Nature 508: 5560, 2014. [Erratum in Nature 508(7494):55-60, 2014] doi:10.1038/ nature 13165 .

29. Heinze C, Seniuk A, Sokolov MV, Huebner AK, Klementowicz AE, Szijártó IA, Schleifenbaum J, Vitzthum H, Gollasch M, Ehmke H, Schroeder BC, Hübner CA. Disruption of vascular Ca2+-activated chloride currents lowers blood pressure. I Clin Invest 124: 675-686, 2014. doi:10.1172/JCI70025.

30. Hellström M, Gerhardt H, Kalén M, Li X, Eriksson U, Wolburg H, Betsholtz C. Lack of pericytes leads to endothelial hyperplasia and abnormal vascular morphogenesis. J Cell Biol 153: 543-553, 2001. doi:10.1083/ jcb.153.3.543.

31. Hirschi KK, Rohovsky SA, Beck LH, Smith SR, D'Amore PA. Endothelial cells modulate the proliferation of mural cell precursors via platelet-derived growth factor-BB and heterotypic cell contact. Circ Res 84: 298-305, 1999. doi:10.1161/01.RES.84.3.298.

32. Hirschi KK, Burt JM, Hirschi KD, Dai C. Gap junction communication mediates transforming growth factor- $\beta$ activation and endothelial-induced mural cell differentiation. Circ Res 93: 429-437, 2003. doi:10.1161/01. RES.0000091259.84556.D5.

33. Iepsen UW, Munch GDW, Rugbjerg M, Rinnov AR, Zacho M, Mortensen SP, Secher NH, Ringbaek T, Pedersen BK, Hellsten Y, Lange $\mathbf{P}$, Thaning $\mathbf{P}$. Effect of endurance versus resistance training on quadriceps muscle dysfunction in COPD: a pilot study. Int J Chron Obstruct Pulmon Dis 11: 2659-2669, 2016. doi:10.2147/COPD.S114351.

34. Ivy JL, Withers RT, Van Handel PJ, Elger DH, Costill DL. Muscle respiratory capacity and fiber type as determinants of the lactate threshold. $J$ Appl Physiol 48: 523-527, 1980. doi:10.1152/jappl.1980.48.3.523.

35. Jain RK. Molecular regulation of vessel maturation. Nat Med 9: 685-693, 2003. doi:10.1038/nm0603-685.

36. Kisler K, Nelson AR, Rege SV, Ramanathan A, Wang Y, Ahuja A, Lazic D, Tsai PS, Zhao Z, Zhou Y, Boas DA, Sakadzõić S, Zlokovic BV. Pericyte degeneration leads to neurovascular uncoupling and limits oxygen supply to brain. Nat Neurosci 20: 406-416, 2017. doi:10.1038/nn.4489.

37. Klement W, Garbelli R, Zub E, Rossini L, Tassi L, Girard B, Blaquiere M, Bertaso F, Perroy J, de Bock F, Marchi N. Seizure progression and inflammatory mediators promote pericytosis and pericyte-microglia clustering at the cerebrovasculature. Neurobiol Dis 113: 70-81, 2018. doi:10.1016/ j.nbd.2018.02.002.

38. Kloner RA, King KS, Harrington MG. No-reflow phenomenon in the heart and brain. Am J Physiol Heart Circ Physiol 315: H550-H562, 2018. doi:10.1152/ajpheart.00183.2018

39. Kofler NM, Cuervo H, Uh MK, Murtomäki A, Kitajewski J. Combined deficiency of Notch1 and Notch3 causes pericyte dysfunction, models CADASIL, and results in arteriovenous malformations. Sci Rep 5: 16449, 2015. doi:10.1038/srep16449.

40. Lahousse L, Tiemeier H, Ikram MA, Brusselle GG. Chronic obstructive pulmonary disease and cerebrovascular disease: A comprehensive review. Respir Med 109: 1371-1380, 2015. doi:10.1016/j.rmed.2015.07.014.

41. Lindsey ML, Gray GA, Wood SK, Curran-Everett D. Statistical considerations in reporting cardiovascular research. Am J Physiol Heart Circ Physiol 315: H303-H313, 2018. doi:10.1152/ajpheart.00309.2018.

42. Liu X, Terry T, Pan S, Yang Z, Willerson JT, Dixon RAF, Liu Q. Targeted delivery of carbaprostacyclin to ischemic hindlimbs enhances adaptive remodeling of the microvascular network. Hypertension 61: 10361043, 2013. [Erratum in Hypertension 61(5):1036-1043, 2013] doi:10.1161/ HYPERTENSIONAHA.111.00458.

43. Lombard JH. A novel mechanism for regulation of retinal blood flow by lactate: gap junctions, hypoxia, and pericytes. Am J Physiol Heart Circ Physiol 290: H921-H922, 2006. doi:10.1152/ajpheart.01268.2005.

5. Maltais F, Decramer M, Casaburi R, Barreiro E, Burelle Y, Debigaré R, Dekhuijzen PN, Franssen F, Gayan-Ramirez G, Gea J, Gosker HR, Gosselink R, Hayot M, Hussain SNA, Janssens W, Polkey MI, Roca J, Saey D, Schols AMWJ, Spruit MA, Steiner M, Taivassalo T, Troosters T, Vogiatzis I, Wagner PD; ATS/ERS Ad Hoc Committee on Limb Muscle Dysfunction in COPD. An official American Thoracic Society/ European Respiratory Society statement: update on limb muscle dysfunction in chronic obstructive pulmonary disease. Am J Respir Crit Care Med 189: e15-e62, 2014. doi:10.1164/rccm.201402-0373ST. 
46. Methner C, Mishra A, Golgotiu K, Li Y, Wei W, Yanez ND, Zlokovic B, Wang RK, Alkayed NJ, Kaul S, Iliff JJ. Pericyte constriction underlies capillary derecruitment during hyperemia in the setting of arterial stenosis. Am J Physiol Heart Circ Physiol 317: H255-H263, 2019. doi:10.1152/ ajpheart.00097.2019.

47. Mogensen C, Bergner B, Wallner S, Ritter A, d'Avis S, Ninichuk V, Kameritsch P, Gloe T, Nagel W, Pohl U. Isolation and functional characterization of pericytes derived from hamster skeletal muscle. Acta Physiol (Oxf) 201: 413-426, 2011. doi:10.1111/j.1748-1716.2010.02206.x.

48. Munroe M, Dvoretskiy S, Lopez A, Leong J, Dyle MC, Kong H, Adams CM, Boppart MD. Pericyte transplantation improves skeletal muscle recovery following hindlimb immobilization. FASEB J 33: 7694-7706, 2019. doi:10.1096/fj.201802580R.

49. Ozerdem U, Grako KA, Dahlin-Huppe K, Monosov E, Stallcup WB. NG2 proteoglycan is expressed exclusively by mural cells during vascular morphogenesis. Dev Dyn 222: 218-227, 2001. doi:10.1002/dvdy.1200.

50. Persidsky Y, Hill J, Zhang M, Dykstra H, Winfield M, Reichenbach NL, Potula R, Mukherjee A, Ramirez SH, Rom S. Dysfunction of brain pericytes in chronic neuroinflammation. $J$ Cereb Blood Flow Metab 36: 794-807, 2016. doi:10.1177/0271678X15606149.

51. Pfister F, Feng Y, vom Hagen F, Hoffmann S, Molema G, Hillebrands J-L, Shani M, Deutsch U, Hammes HP. Pericyte migration: a novel mechanism of pericyte loss in experimental diabetic retinopathy. Diabetes 57: 2495-2502, 2008. doi:10.2337/db08-0325.

52. Pinheiro J, Bates D, DebRoy S, Sarkar D; R Core Team (2014). nlme linear and nonlinear mixed effects models. $R$ package version 3.1-117. https://CRAN.R-project.org/package=nlme.

53. Pinto-Plata V, Casanova C, Müllerova H, de Torres JP, Corado H, Varo N, Cordoba E, Zeineldine S, Paz H, Baz R, Divo M, Cortopassi F, Celli BR. Inflammatory and repair serum biomarker pattern: association to clinical outcomes in COPD. Respir Res 13: 71, 2012. [Erratum in Respir Res.: https://doi.org/10.1186/1465-9921-13-71] doi:10.1186/1465-9921-1371.

54. Pinto-Plata V, Toso J, Lee K, Park D, Bilello J, Mullerova H, De Souza MM, Vessey R, Celli B. Profiling serum biomarkers in patients with COPD: associations with clinical parameters. Thorax 62: 595-601, 2007. doi:10.1136/thx.2006.064428.

55. Poole DC, Copp SW, Hirai DM, Musch TI. Dynamics of muscle microcirculatory and blood-myocyte $\mathrm{O}(2)$ flux during contractions. Acta Physiol (Oxf) 202: 293-310, 2011. doi:10.1111/j.1748-1716.2010.02246.x.

56. Poole DC, Richardson RS. Determinants of oxygen uptake. Implications for exercise testing. Sports Med 24: 308-320, 1997. doi:10.2165/00007256199724050-00003.

57. Qin D, Trenkwalder T, Lee S, Chillo O, Deindl E, Kupatt C, Hinkel R. Early vessel destabilization mediated by Angiopoietin-2 and subsequent vessel maturation via Angiopoietin-1 induce functional neovasculature after ischemia. PLoS One 8: e61831, 2013. doi:10.1371/journal.pone.0061831.

58. Richardson RS, Leek BT, Gavin TP, Haseler LJ, Mudaliar SRD, Henry R, Mathieu-Costello O, Wagner PD. Reduced mechanical efficiency in chronic obstructive pulmonary disease but normal peak VO2 with small muscle mass exercise. Am J Respir Crit Care Med 169: 89-96, 2004. doi:10.1164/rccm.200305-6270C.

59. Rossi E, Smadja D, Goyard C, Cras A, Dizier B, Bacha N, Lokajczyk A, Guerin CL, Gendron N, Planquette B, Mignon V, Bernabéu C, Sanchez O, Smadja DM. Co-injection of mesenchymal stem cells with endothelial progenitor cells accelerates muscle recovery in hind limb ischemia through an endoglin-dependent mechanism. Thromb Haemost 117: 1908-1918, 2017. doi:10.1160/TH17-01-0007.

60. Rossi E, Smadja DM, Boscolo E, Langa C, Arevalo MA, Pericacho M, Gamella-Pozuelo L, Kauskot A, Botella LM, Gaussem P, Bischoff J, Lopez-Novoa JM, Bernabeu C. Endoglin regulates mural cell adhesion in the circulatory system. Cell Mol Life Sci 73: 1715-1739, 2016. doi:10.1007/ s00018-015-2099-4.

61. Sato T, Haimovici R, Kao R, Li A-F, Roy S. Downregulation of connexin 43 expression by high glucose reduces gap junction activity in microvascular endothelial cells. Diabetes 51: 1565-1571, 2002. doi:10.2337/diabetes. 51.5.1565.

62. Schmid F, Reichold J, Weber B, Jenny P. The impact of capillary dilation on the distribution of red blood cells in artificial networks. Am J Physiol Heart Circ Physiol 308: H733-H742, 2015. doi:10.1152/ ajpheart.00335.2014.

63. Sõpiranec K, Chen W, Werner F, Nikolaev VO, Naruke T, Koch F, Werner A, Eder-Negrin P, Diéguez-Hurtado R, Adams RH, Baba HA, Schmidt H, Schuh K, Skryabin BV, Movahedi K, Schweda F, Kuhn M. Endothelial C-type natriuretic peptide acts on pericytes to regulate microcirculatory flow and blood pressure. Circulation 138: 494-508, 2018. doi:10.1161/CIRCULATIONAHA.117.033383.

64. Spruit MA, Singh SJ, Garvey C, ZuWallack R, Nici L, Rochester C, Hill K, Holland AE, Lareau SC, Man WD-C, Pitta F, Sewell L, Raskin J, Bourbeau J, Crouch R, Franssen FME, Casaburi R, Vercoulen JH, Vogiatzis I, Gosselink R, Clini EM, Effing TW, Maltais F, van der Palen J, Troosters T, Janssen DJA, Collins E, Garcia-Aymerich J, Brooks D, Fahy BF, Puhan MA, Hoogendoorn M, Garrod R, Schols AMWJ, Carlin B, Benzo R, Meek P, Morgan M, Rutten-van Mölken MPMH, Ries AL, Make B, Goldstein RS, Dowson CA, Brozek JL, Donner CF, Wouters EFM; ATS/ERS Task Force on Pulmonary Rehabilitation. An official American Thoracic Society/European Respiratory Society statement: key concepts and advances in pulmonary rehabilitation. Am J Respir Crit Care Med 188: e13-e64, 2013. doi:10.1164/ rccm.201309-1634ST.

65. Stallcup WB. The NG2 proteoglycan: past insights and future prospects. $J$ Neurocytol 31: 423-435, 2002. doi:10.1023/a:1025731428581.

66. Stapor PC, Azimi MS, Ahsan T, Murfee WL. An angiogenesis model for investigating multicellular interactions across intact microvascular networks. Am J Physiol Heart Circ Physiol 304: H235-H245, 2013. doi:10.1152/ajpheart.00552.2012.

67. Stoebner P, Mezin P, Vila A, Grosse R, Kopp N, Paramelle B. Microangiopathy of endoneurial vessels in hypoxemic chronic obstructive pulmonary disease (COPD). A quantitative ultrastructural study. Acta Neuropathol 78: 388-395, 1989. doi:10.1007/BF00688175.

68. van Rijen HV, van Kempen MJ, Postma S, Jongsma HJ. Tumour necrosis factor $\alpha$ alters the expression of connexin43, connexin40, and connexin37 in human umbilical vein endothelial cells. Cytokine 10: 258-264, 1998. doi:10.1006/cyto.1997.0287.

69. Vogelmeier CF, Criner GJ, Martinez FJ, Anzueto A, Barnes PJ, Bourbeau J, Celli BR, Chen R, Decramer M, Fabbri LM, Frith P, Halpin DMG, López Varela MV, Nishimura M, Roche N, RodriguezRoisin R, Sin DD, Singh D, Stockley R, Vestbo J, Wedzicha JA, Agustí A. Global Strategy for the Diagnosis, Management, and Prevention of Chronic Obstructive Lung Disease 2017 Report. GOLD Executive Summary. Am J Respir Crit Care Med 195: 557-582, 2017. doi:10.1164/ rccm.201701-0218PP

70. Vogiatzis I, Terzis G, Nanas S, Stratakos G, Simoes DC, Georgiadou O, Zakynthinos S, Roussos C. Skeletal muscle adaptations to interval training in patients with advanced COPD. Chest 128: 3838-3845, 2005. doi:10.1378/ chest.128.6.3838.

71. Vono R, Fuoco C, Testa S, Pirrò S, Maselli D, Ferland McCollough D, Sangalli E, Pintus G, Giordo R, Finzi G, Sessa F, Cardani R, Gotti A, Losa S, Cesareni G, Rizzi R, Bearzi C, Cannata S, Spinetti G, Gargioli C, Madeddu P. Activation of the pro-oxidant PKCBII-p66Shc signaling pathway contributes to pericyte dysfunction in skeletal muscles of patients with diabetes with critical limb ischemia. Diabetes 65: 3691-3704, 2016. doi:10.2337/db16-0248. 